\title{
OPTIMIZATION OF ORDER-PICKING SYSTEMS THROUGH TACTICAL AND OPERATIONAL DECISION MAKING
}

\author{
Kovac, M. \& Djurdjevic, D. \\ Faculty of Transport and Traffic Engineering, University of Belgrade, Serbia \\ E-Mail: kovac.milovan@ hotmail.com,d.djurdjevic@sf.bg.ac.rs
}

\begin{abstract}
Order picking (OP) is a process that occurs in warehouses of unitized goods and it includes all activities that follow the retrieval of demanded goods, according to demanded type and quantity, with the intention of meeting customer demands, accurately and on time, with acceptable costs. As the OP process can contribute up to $50 \%$ to the overall warehouse operational costs, design of the order picking system (OPS) needs special attention during the warehouse design process. In existing systems, the need for improvement is often caused by the change in demands. This paper analyses the possibilities of low-level picker-to-part OPS improvement through appropriate decision making on different design levels: tactical and operational. In this paper, a simulation-analytical model is developed to evaluate different OPS scenarios based on three storage assignment policies, four routing strategies and two different OP methods. Two layout variants and the evaluation of the required workforce are considered as well. The experiment results indicate that the application of the proposed model could lead to significant improvements regarding OPS performances and resource utilization. (Received in October 2019, accepted in January 2020. This paper was with the authors 2 weeks for 1 revision.)
\end{abstract}

Key Words: Warehouse Design, Order-Picking, System Approach, Simulation

\section{INTRODUCTION}

Warehouses, as one of the key elements needed for the realization of material flow, represent one of the essential links of a supply chain [1]. The efficient management of material (raw materials, product components and finished products) flows requires hard work on the field of optimization of all processes relevant for warehouse management. Warehouse's purpose is determined by its role in the supply chain. Considering that, the goal of the warehouse design process is to create a solution that fulfils the warehouse objective in the best manner possible [2].

More complex customer demands from the aspect of product assortment and quantity, as well in the logistics service quality, are increasing the importance of the optimization of distribution warehouse processes. The adoption of new management philosophies (such as Just-in-Time, lean production, etc.) and intensive market competition require higher performance from warehouses [3]. The emergence of heterogeneous dispatch unit demands results in the need for the forming of such a unit through the process of order-picking (OP). $\mathrm{OP}$ is a process that occurs in warehouses of unitized goods and it includes all activities that follow the retrieval of demanded goods, according to type and quantity, intending to meet customer demands, accurately and on time, with acceptable costs [2].

As OP is the most labour-intensive process in the warehouse, the performance of the whole system is strongly dependent on the efficiency of the order-picking system (OPS). According to [4], OP is the highest priority activity to improve productivity in a warehouse (distribution centre) due to its high contribution to the total operating costs of a distribution centre. It can be even stated that the service-level and performances of the whole supply chain rests upon the efficiency of the OPS. Due to its importance, a special focus should be set on the designing of the OPS during the warehouse design process. The design of the OPS considers decisions that could be classified into three hierarchical levels: strategic, tactical and operational decisions [1]. Strategic level decisions have a long-term impact and they refer to 
decisions concerning the design of the process flow and those concerning the selection of the types of warehousing systems. Tactical level decisions refer to estimating resources needed and choosing the layout of the system, and as such, they have a medium-term impact on the system. Operational level decisions refer to the problems of direct process organization and they include OP routing, job assignment, storage assignment, OP method selection, etc. The OPS efficiency depends on the project itself (storage and OP technology selection, layout, system dimensioning, operating rules, etc.), the way the design process requests are met, and the way OP activities are operated and executed.

During the exploitation of the system and/or with the change in demands, the system could face certain inefficiencies that reflect on productivity, accuracy, resource utilization, etc. Those inefficiencies are causing the need for a system redesign. The OP improvement possibilities lay in many different aspects of the problem [5] such as layout, storage assignment, routing, order batching, etc. All OPS design problems are interdependent but taking all of them into consideration is intractable. In most cases, the researchers are focused only on few different OPS design problems and the literature is very scarce in examining the interdependence between more than three key factors that affect the OPS design process [6].

The purpose of this paper is to analyse the possibilities of OP process optimization through minor system adjustments on the tactical and operational level design decision making. The analysis is focused on low-level picker-to-part OPS as a dominant type of OPSs that are applied in practice [5]. A rectangular warehouse with parallel aisles is analysed. The order pickers can change aisles from the front or the rear end of the storage area. The depot is located in front of the first aisle to the left. The aisles are wide enough to support two-way travel, but due to safety measures, an aisle could be visited only by one picker at a time.

Systematically, the proposed simulation-analytical model can simultaneously tackle some relevant questions regarding OPS design on the tactical and operational level. More specifically, the model allows analysis of three storage assignment policies, four routing strategies, and two OP methods, as well as analysis of the effects of separating the OP area into two blocks. Moreover, the model helps answering several key questions regarding OPS design, and it could be easily applied for a wider set of input parameters and used for evaluation of different tactical and operational OPS variants.

The remainder of the paper is organized as follows: In Section 1 a short literature review about OPS improvement is presented. In this section, all relevant questions regarding OPS optimization are explained. In Section 2 the methodology for evaluation of the OPS variants is presented. In Section 3 the methodology is tested. In Section 4 results are analysed and the last section represents concluding remarks.

\section{LITERATURE REVIEW}

In this chapter, the literature review regarding the aspects relevant to this paper is presented. The focus is set on the OPS design process and all relevant questions that follow.

The problem of designing and optimizing the OPS has attracted a lot of attention in the literature over the years. However, despite the OPS importance, the literature still lacks a precisely defined procedure for designing of the OPS in a systematic manner [7]. Some of the most researched problems regarding the OPS optimization covered in the literature are layout design [8, 9], storage assignment [10-12], order-picker routing [13-15] and order batching $[3,16,17]$. In the next sections, the relevant questions regarding OPS design and improvement will be explained. 


\subsection{Layout}

In warehouses (and material handling systems in general), two categories of layout problems are present [5]. Facility layout problem, as the first category, refers to problems of department allocation within a facility. The second category of layout problems - internal layout refers to determining the physical dimensions of a single area. In the context of OPS, the layout problem refers to the number of blocks, cross aisles positions, number of vertical aisles and vertical aisle length of the OP area [5]. A layout variant is defined by combining different setups of these parameters. Adding cross-aisles to OP area layout allows greater flexibility in order picking routing and therefore provides shorter order picking travel distances $[18,19]$. In this paper, the internal layout problem considering cross-aisle position will be analysed.

\subsection{Estimating the resources needed}

One of the key tactical level questions is how many resources are needed in order to fulfil the objective with desired performances. The literature regarding warehouse workforce level estimation is very limited [20]. Since the OP area is a work-intensive area, it is common that congestions occur. Some of the papers in the literature consider congestion situations in warehouses caused by the presence of multiple pickers [21, 22]. In this paper, the focus will be set on the number of order-pickers needed to complete the OP process with the desired performances. Order-pickers blocking and congestions in aisles will be taken into account during OPS variants evaluation.

\subsection{Storage location assignment}

Storage location assignment has been recognized in the literature as one of the factors that have a great impact on the OPS performances. Various storage assignment policies have been developed, such as randomized storage policy (RSP), class-based storage policy (CBS), dedicated storage policy (DSP), storage assignment based on the cube-per-order index (COI), order-oriented slotting (OOS) and many hybrid policies. In RSP there is an equal possibility for any stock keeping unit (SKU) to be stored on any available location [14], while in DSP every SKU has a dedicated storage location and only that particular SKU could be stored on that location. The CBS stands between the RSP and DSP and under that policy the SKUs are first classified into classes (based on frequency, volume, type, etc.) and every class has a determined storage area while the SKUs inside a class are stored randomly in the storage area for that particular class [11]. Prior to applying COI based policy, the COI for every SKU is calculated and the SKUs are sorted according to the COI in ascending order. After that, the SKUs with lesser COI value are assigned to more favourable storage locations. The idea behind OOS is to allocate SKUs that occur frequently on the same orders close to each other in the OP area [12]. The hybrid storage policies combine the advantages of two or more storage policies. They are often used in practice in order to satisfy additional system constraints $[23,24]$. In this paper, RSP, CBS and OOS storage assignment policies will be considered.

\subsection{Order-picker routing}

The goal of order-picker routing is to determine the sequence of locations that an order-picker should visit in one tour. This is probably the most covered operational level problem in the literature. There are several different routing policies that are frequently applied in real life warehouses. The simplest heuristic is the S-Shape (traversal) policy [25]. Under this policy, the order-picker traverses all aisles that contain at least one SKU from the order. Using the largest gap routing policy for every aisle the largest gap (either the distance between two 
adjacent pick locations or between aisle end and its closest pick location) is determined [26]. During a cycle, the order-picker traverses the first and the last aisle (that contain SKUs for picking) entirely, while all aisles in between are visited as far as the largest gap from either side. The mid-point policy splits the OP area into two halves. SKUs located in the front half of an aisle are visited from the front cross-aisle, while SKUs from the other half of the aisle are reached from the opposite cross-aisle. In order of completing a cycle, the first and the last aisle that contain picking SKUs are traversed entirely. Beside the mentioned heuristics, there are also approaches that aim to construct the optimal route in an OP area [13]. Optimization approaches are rarely used in practice and more in literature for benchmarking purposes. We assume that with some additional computing effort, the optimization approaches could be used in practice effectively. All previously mentioned approaches are of a static nature, which means that a constructed order-picker route is fixed when determined. Since congestions can occur when more than one order-picker traverses an aisle, sometimes it is more convenient for an order-picker to visit another aisle that is not occupied by other order-pickers. In [27] an ant colony optimization approach is used for dynamic order-picker routing with multiple pickers.

In this paper, the routing policies that will be considered are traversal, largest gap, optimal and adaptive policy. Under the adaptive policy, the order-pickers will enter the closest nonoccupied aisle that contains SKUs from their order for picking. When the order-picker finishes picking all requested SKUs in an aisle, he leaves the aisle on the closest end from his current position. The idea behind adaptive routing policy is to reduce waiting times in the OP area. The application of any adaptive OP routing strategy requires a sophisticated warehouse management system with real-time OP management functionality. Also, applying this routing strategy is only possible when there is no particular order in which the pallet layers must be stacked.

\subsection{OP method selection}

OP method is defined as the way the process is organized. There are three main types of OP methods present in literature: single, batch and zone picking. Also, it is possible to combine different OP methods. The selection of the appropriate OP method depends on order profiles [28]. An order profile contains the quantity of orders and the item number of SKUs that should be picked in every order. In single order picking, every order is individually assigned to an order-picker and solved. Batching orders refers to joining multiple orders into a single order, and further on the orders are completed at the same time. Depending on when the sorting of joined orders occurs, two OP methods with batched orders could be distinguished: sort-while-pick and pick-and-sort. In sort-while-pick OP method the joined orders are sorted during the picking process, while under the pick-and-sort OP method, orders are sorted after the picking is done. Orders can be batched if they do not exceed the capacity of the loading unit and the applied picking technology. Also, batching orders is possible only if their order lead times are compatible. The application of pick-and-sort OP method requires additional space and resources for the sorting activities. Order batching can reduce order-picker travelling distance [29]. There are many different algorithms (first-come-first-served algorithm, seed algorithms, saving algorithms, etc.) and approaches used for order batching [30]. Good literature reviews on batching policies are given in $[1,3,16]$.

Under the zone picking method, every picker is assigned to a specific zone in the OP area and works only within that zone. This means that every order that has SKUs located in more than one zone is picked by multiple pickers. Picking an order with multiple pickers can be executed sequentially or simultaneously. Zone picking could be combined with single and batch picking methods. The application of zone picking OP method requires additional consolidation and sorting activities (except in the case of pick and pass OP method). 
The literature on zoning is rather limited. For more details, the reader should see [5, 31]. In this paper, single and batch (sort-while-pick) OP methods are considered. A savings-based algorithm is used for batching orders in the sort-while-pick OP method. Under this algorithm, for every single order, a list of correlation coefficients with all other orders is formed. The correlation coefficient is calculated according to the number of common aisles between two orders that contain SKUs for picking. The orders pair that has the highest correlation coefficient is batched together. Two orders are batched only if none of them exceeds the capacity of one pallet (100 cases per pallet). The iteration process is repeated until there are no orders that could be batched together. Batching orders that exceed the defined capacity would require additional sorting activities after the picking process is finished, and as that, it does not fit the sort-while-pick OP method.

\subsection{Systematic approach in OPS design process}

Due to the complexity and interdependence of modern logistics problems, solving them separately can only lead to suboptimal solutions. The secret of obtaining optimal solutions in logistics lays in a systematic approach when solving problems. A literature review regarding combining different planning problems during the OPS design process is presented in [6]. The authors state that some of the problems have been simultaneously analysed and solved, but that the literature has some gaps, especially in solving more than three different problems at once. The most frequently combined problems that are solved in the literature are: storage assignment and routing [32, 33], storage assignment and order batching [34] and routing and order batching [35].

During the OPS design, it is very important to obtain a complete picture regarding the possible performances that the designed system could reach. As mentioned, the only way of completing the picture is in the system approach. It is also, very important to define the performances that will reflect the system's effectiveness. In most of the literature, the focus is set on the travelling distance. The goal of this paper is to consider multiple decisions, and different performance measures as well. The results indicate that observing different performances will give different solutions regarding the analysed OPS variants. The performance measures considered in this paper are travelling distance, completion time and picker waiting time.

\section{METHODOLOGY DEVELOPMENT}

The methodology consists of two phases. Prior to the first phase, since the redesign of existing OPS is in focus, all relevant questions regarding strategic level decisions need to be answered. Considering the OPS, OP area capacity and technology have to be determined. In the first phase, all possible variants of the OPS regarding different tactical and operational level decisions are generated. To evaluate the effectiveness of different OPS variants, all relevant performance measures need to be defined as well. The first phase of the model is presented in Fig. 1 a.

In the analytical phase of the model, every OPS variant is applied over every defined layout variant. In this phase, through an iterative process, for every OPS-layout combination performance indicators for a given number of resources are calculated. OP cycle time $\left(O P C_{t}\right)$ components taken into account are travelling time $\left(T_{\text {travel }}\right.$, dependent on the distance), case searching and picking time $\left(T_{s}, 5 \mathrm{~s}\right.$ per case), waiting time $\left(T_{w}\right.$, simulated) and unit dispatching time ( $T_{d}, 10 \mathrm{~s}$ per unit). OP cycle time calculation is presented in Eq. (1).

$$
O P C_{t}=T_{\text {travel }}+T_{s}+T_{w}+T_{d}
$$


The number of resources is incremented if none of the OPS variants gives the desired performances. When at least one OPS variant with desired performances emerges, the iteration process terminates. After the iteration process, the best OPS variant could be selected. The analytical phase of the model is shown in Fig. $1 \mathrm{~b}$.
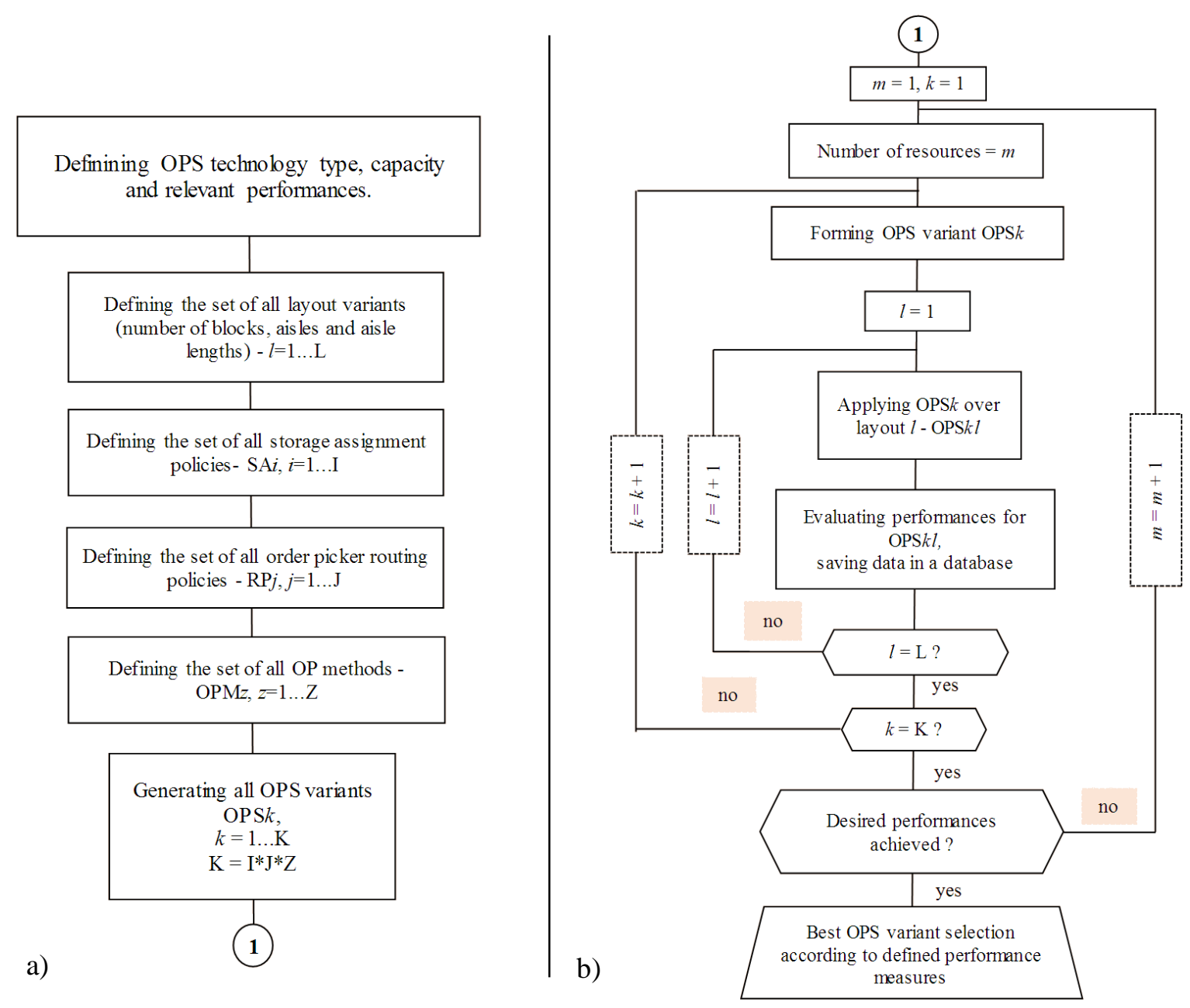

Figure 1: Proposed methodology: a) initial phase; b) analytical phase.

\section{CASE DESCRIPTION}

The OPS that will be analysed in this paper is a real-life system from one Serbian 3PL $\left(3^{\text {rd }}\right.$ Party Logistics) company warehouse. The applied type of OPS is the manual low-level picker-to-parts system. The layout consists of one block with 8 aisles with $3 \mathrm{~m}$ width. The capacity of the OP area is 800 storage locations, and every aisle is composed of 50 storage locations from both sides. After applying ABC analysis, the following order pattern has been observed:

Group A consists of $20 \%$ of all SKUs and these SKUs appear on $70 \%$ of the orders. Group B consists of $35 \%$ of all SKUs and these SKUs appear on $20 \%$ of the orders. Group C consists of $45 \%$ of all SKUs, but they appear only in $10 \%$ of all the orders. The number of different SKUs on one order is following the uniform distribution between 5 and 20: $\mathrm{U}(5,20)$, while the number of cases per SKU is uniformly distributed between the values 1 and $10, \mathrm{U}(1,10)$.

After receiving a picking list, the order-picker visits the picking locations according to a picking sequence. To pick the listed SKUs, the order-picker has to traverse certain aisles in the OP area. Warehouse safety measures and standards prohibit simultaneous aisle traversing 
by multiple order-pickers. This means that order-pickers must wait for the aisle to be empty to visit it. Time spent in an aisle depends on the aisle traversing and SKU picking time. Orderpicker travelling time is dependent on the distance and travelling speed $(2 \mathrm{~m} / \mathrm{s})$, while the SKU picking time depends on the demanded quantity of that particular SKU that is on the picking list. It is assumed that the time needed for case searching and picking is $5 \mathrm{~s}$ per case. When the order-picker finishes picking all the SKUs from the picking list, he returns to the depot and dispatches the formed unit (dispatching time is assumed to be $10 \mathrm{~s}$ per unit). Orderpickers continue to receive picking lists until there is no picking list left, or their working shift has ended.

The applied storage assignment policy is RSP with S-shape routing policy and single OP method and the applied technology is low-level OP. The number of workers $(\mathrm{m})$ that simultaneously operate in the OP area is 6 . The observed OPS performances indicate that on a daily basis the system can't complete 500 orders as demanded. The main question is whether or not the current OPS could achieve the performances needed for completing 500 orders on a daily basis ( 2 work shifts, 8 hours per shift) through interventions in the tactical and operational level of decision making.

Solving the stated problem includes examining all the decisions on tactical and operational levels which will redesign the existing OPS. In this study, some of the most applied variants for different problems are taken into consideration. Three different storage location assignment policies (RSP, CBS and OOS), four routing strategies (S-Shape, Largest Gap, Optimal and Adaptive) and two OP methods (single OP and sort-while-pick OP) are considered. In the OOS policy, the number of clusters for SKU grouping will be equal to the number of vertical aisles in the OP area. Combining different policies regarding these three questions, 24 different OPS variants emerged. The analysed OPS variants are shown in Table I. Since the number of aisles is fixed, considering the layout interventions, separating the OP area into two blocks will be taken into account. The model has been developed in Python 3.7 programming language with SymPy library.

Table I: Analysed OPS variants.

\begin{tabular}{|c|c|c|c|c|c|c|c|c|c|}
\hline \multirow{2}{*}{$\begin{array}{c}\text { OPS } \\
\text { variant }\end{array}$} & \multicolumn{3}{|c|}{ Storage assignment } & \multicolumn{4}{|c|}{ Routing policy } & \multicolumn{2}{|c|}{ OP method } \\
\hline & RSP & CBS & OOS & S-Shape & Largest Gap & Optimal & Adaptive & Single & Sort-while-pick \\
\hline OPS 1 & $*$ & & & $*$ & & & & $*$ & \\
\hline OPS 2 & * & & & * & & & & & $*$ \\
\hline OPS 3 & $*$ & & & & $*$ & & & * & \\
\hline OPS 4 & $*$ & & & & $*$ & & & & $*$ \\
\hline OPS 5 & * & & & & & $*$ & & * & \\
\hline OPS 6 & * & & & & & $*$ & & & $*$ \\
\hline OPS 7 & * & & & & & & $*$ & $*$ & \\
\hline OPS 8 & * & & & & & & $*$ & & $*$ \\
\hline OPS 9 & & * & & $*$ & & & & * & \\
\hline OPS 10 & & $*$ & & $*$ & & & & & * \\
\hline OPS 11 & & $*$ & & & $*$ & & & * & \\
\hline OPS 12 & & $*$ & & & $*$ & & & & $*$ \\
\hline OPS 13 & & $*$ & & & & $*$ & & $*$ & \\
\hline OPS 14 & & $*$ & & & & $*$ & & & * \\
\hline OPS 15 & & $*$ & & & & & $*$ & * & \\
\hline OPS 16 & & $*$ & & & & & $*$ & & $*$ \\
\hline OPS 17 & & & $*$ & $*$ & & & & $*$ & \\
\hline OPS 18 & & & $*$ & $*$ & & & & & * \\
\hline OPS 19 & & & $*$ & & $*$ & & & * & \\
\hline OPS 20 & & & $*$ & & $*$ & & & & $*$ \\
\hline OPS 21 & & & $*$ & & & $*$ & & $*$ & \\
\hline OPS 22 & & & $*$ & & & $*$ & & & $*$ \\
\hline OPS 23 & & & $*$ & & & & $*$ & $*$ & \\
\hline OPS 24 & & & $*$ & & & & $*$ & & $*$ \\
\hline
\end{tabular}




\section{FINDINGS}

After the model application, several OPS variants have emerged as good solutions. The best OPS variants according to the model are shown in Table II (the current OPS variant performances are shown in the first row - OPS 1). The performance measures that single out some of the OPS variants as the best are highlighted.

Table II: Best OPS variants.

\begin{tabular}{|l|c|c|c|c|c|c|c|c|}
\hline $\begin{array}{l}\text { OPS } \\
\text { variant }\end{array}$ & $\begin{array}{c}\text { Storage } \\
\text { assignment } \\
\text { policy }\end{array}$ & $\begin{array}{c}\text { Routing } \\
\text { policy }\end{array}$ & OP method & $\begin{array}{c}\text { Number } \\
\text { of order- } \\
\text { pickers }\end{array}$ & $\begin{array}{c}\text { Cross- } \\
\text { aisle } \\
\text { position }\end{array}$ & $\begin{array}{c}\text { Distance } \\
\text { travelled } \\
(\mathrm{km})\end{array}$ & $\begin{array}{c}\text { Completion } \\
\text { time (h) }\end{array}$ & $\begin{array}{c}\text { Average } \\
\text { waiting } \\
\text { time (h) }\end{array}$ \\
\hline \hline OPS 1 & RSP & S-Shape & Single & 6 & - & 199.99 & 16.43 & 3.61 \\
\hline OPS 2 & RSP & S-Shape & Sort-while-pick & 5 & - & 108.86 & 14.75 & 2.01 \\
OPS 6 & RSP & Optimal & Sort-while-pick & 5 & - & 97.89 & 15.87 & 3.46 \\
OPS 10 & CBS & S-Shape & Sort-while-pick & 5 & - & 92.68 & 15.79 & 3.53 \\
OPS 18 & OOS & S-Shape & Sort-while-pick & 5 & - & 102.33 & 14.99 & 2.43 \\
OPS 20 & OOS & Largest Gap & Sort-while-pick & 5 & - & 84.95 & 15.16 & 3.09 \\
OPS 22 & OOS & Optimal & Sort-while-pick & 5 & - & 75.05 & 15.38 & 3.59 \\
OPS 8 & RSP & Adaptive & Sort-while-pick & 5 & - & 111.22 & 14.01 & 1.20 \\
OPS 16 & CBS & Adaptive & Sort-while-pick & 5 & - & 86.59 & 15.23 & 3.14 \\
OPS 24 & OOS & Adaptive & Sort-while-pick & 5 & - & 87.51 & 13.69 & 1.56 \\
OPS 21 & OOS & Optimal & Single & 5 & 9 & 103.54 & 14.80 & 2.09 \\
OPS 7 & RSP & Adaptive & Single & 5 & 26 & 167.30 & 15.43 & 0.93 \\
OPS 23 & OOS & Adaptive & Single & 5 & 10 & 127.15 & 14.51 & 1.15 \\
OPS 16 & CBS & Adaptive & Sort-while-pick & 4 & 12 & 86.49 & 15.67 & 0.56 \\
OPS 16 & CBS & Adaptive & Sort-while-pick & 4 & 22 & 84.50 & 15.88 & 0.85 \\
OPS 24 & OOS & Adaptive & Sort-while-pick & 4 & 9 & 85.43 & 15.45 & 0.38 \\
OPS 23 & OOS & Adaptive & Sort-while-pick & 4 & 12 & 84.43 & 15.45 & 0.43 \\
\hline
\end{tabular}

By comparing the current OPS performances with the ones that the model selects as better OPS variants, it is obvious that it is possible to obtain better performances with appropriate tactical and operational level improvement. Considering one-block OP areas, the only way to reach the productivity of 500 orders per day is to use order batching. It can be stated that it is possible to reach desired performances even with a lesser number of resources if appropriate tactical and operational measures are taken. Further reduction in the number of needed resources is possible if the OP area is separated into two blocks. The best OPS variant regarding travelling distance is OPS 22 that uses OOS storage assignment policy, optimal routing policy and sort-while-pick OP method (62.47\% improvement in comparison with OPS 1), but there are better variants regarding completion time and the average waiting time per order-picker. The best variant in terms of completion time is OPS 24 with OOS storage assignment, adaptive routing policy, sort-while-pick OP method and 5 order pickers $(16.67 \%$ improvement in comparison with OPS 1). Regarding the minimal possible number of resources needed and minimal possible waiting times, the best OPS variant is OPS 24 that applies OOS storage assignment policy, adaptive routing policy, sort-while-pick OP method, 4 order pickers and an OP area consisting of two blocks with the cross-aisle on the $9^{\text {th }}$ position ( 2 less order pickers and $89.47 \%$ lesser waiting time in comparison with OPS 1). This OPS variant shows that it is possible to obtain high productivity with a lower number of resources by making appropriate tactical and operational decisions. Taking this into account, we suggest that the observed OPS should consider this variant for implementation. The current and the proposed OP area layout are shown in Fig. 2. 


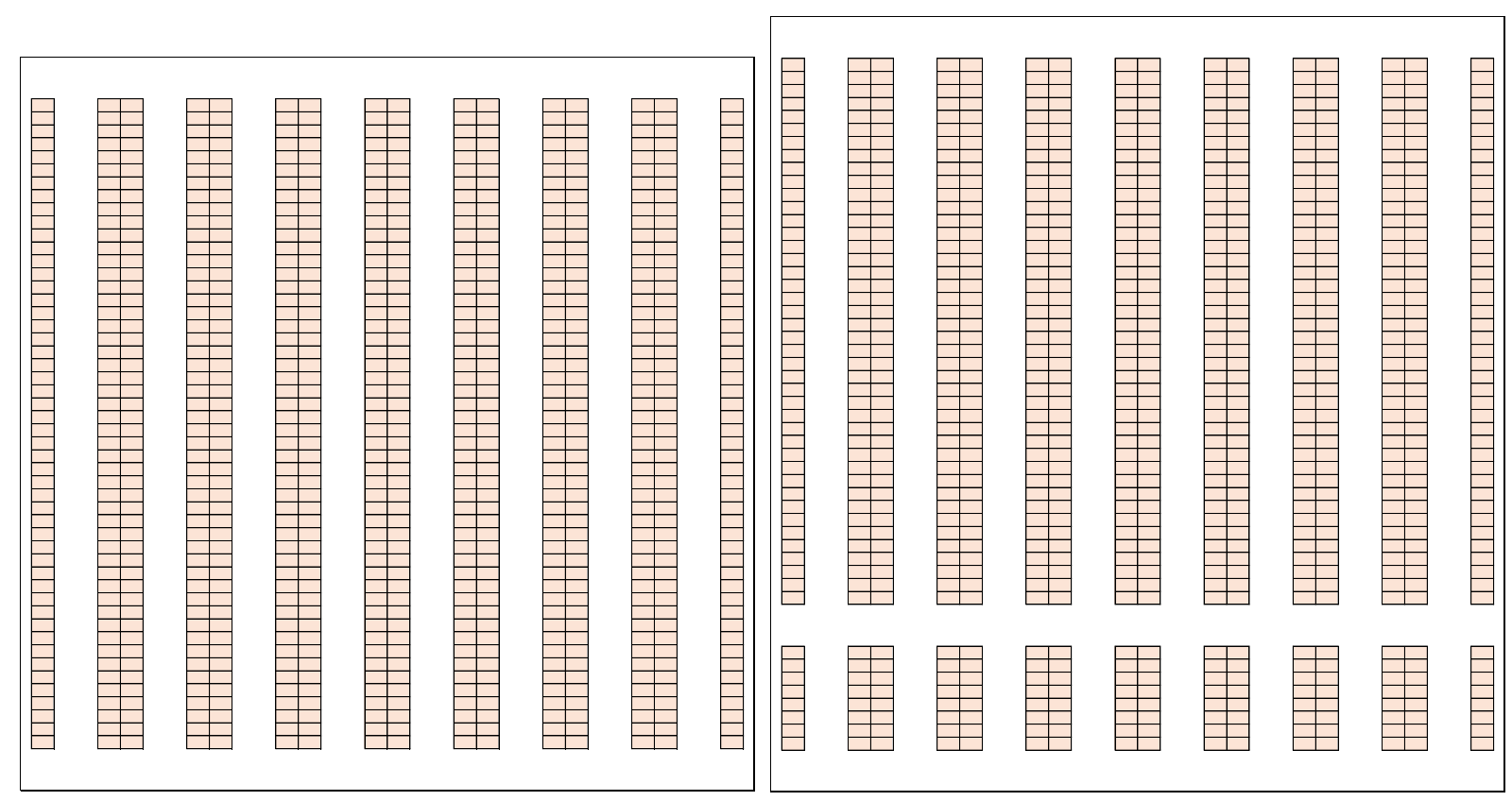

a)

b)

Figure 2: OPS layout: a) current; b) proposed.

\section{CONCLUSION}

Separate problem-solving in logistics can lead only to suboptimal solutions. High-quality answers are resting upon a systematic approach during problem-solving. Also, the selection of appropriate performances for solution quality evaluation is of great importance. The goal of this paper was to underline the significance of systematic approach decision making in OPS improvement. The focus was set on analysing the possibilities of OPS optimization through the scope of simultaneous tactical and operational-level decision making. In this paper, a model for evaluating OPS variants is proposed. The proposed model consists of two phases. In the first phase, all feasible scenarios of different OPS variants were defined, as well as the performance indicators used for scenario evaluation. When defining different OPS variants, the restrictions caused by specific goods and applied technology characteristics should be taken into account. Taking these restrictions into consideration could exclude certain tactical and operational policies. In the second phase, all OPS variants are evaluated and a set of acceptable variants is formed. The optimization of OPS in this paper can give answers on questions regarding tactical and operational level design decisions such as OP layout, storage assignment policy, routing policy, OP method and the required number of resources needed to reach certain goal performances. The model could be easily expanded to include more questions regarding the two levels of decision making, such as job assignment and zoning. The application of this model can be used as a base for decision making and the results could be used as input parameters for a multi-criteria decision-making model (such as weighted evaluation technique, AHP, TOPSIS, etc.).

\section{REFERENCES}

[1] Rouwenhorst, B.; Reuter, B.; Stockrahm, V.; van Houtum, G. J.; Mantel, R. J.; Zijm, W. H. M. (2000). Warehouse design and control: Framework and literature review, European Journal of Operational Research, Vol. 122, No. 3, 515-533, doi:10.1016/S0377-2217(99)00020-X

[2] Djurdjević, D. (2013). Development of Models for Order Picking Area Selection and Design, $\mathrm{PhD}$ Thesis, University of Belgrade, Belgrade 
[3] Gu, J.; Goetschalckx, M.; McGinnis, L. F. (2007). Research on warehouse operation: A comprehensive review, European Journal of Operational Research, Vol. 177, No. 1, 1-21, doi:10.1016/j.ejor.2006.02.025

[4] Tompkins, J. A.; White, J. A.; Bozer, Y. A.; Tanchoco, J. M. A. (2010). Facilities Planning, $4^{\text {th }}$ edition, John Wiley \& Sons, Hoboken

[5] De Koster, R.; Le-Duc, T.; Roodbergen, K. J. (2007). Design and control of warehouse order picking: A literature review, European Journal of Operational Research, Vol. 182, No. 2, 481501, doi:10.1016/j.ejor.2006.07.009

[6] Van Gils, T.; Ramaekers, K.; Caris, A.; de Koster, R. B. M. (2018). Designing efficient order picking systems by combining planning problems: State-of-the-art classification and review, European Journal of Operational Research, Vol. 267, No. 1, 1-15, doi:10.1016/ j.ejor.2017.09.002

[7] Baker, P.; Canessa, M. (2009). Warehouse design: A structured approach, European Journal of Operational Research, Vol. 193, No. 2, 425-436, doi:10.1016/j.ejor.2007.11.045

[8] Roodbergen, K. J.; Sharp, G. P.; Vis, I. F. A. (2008). Designing the layout structure of manual order picking areas in warehouses, IIE Transactions, Vol. 40, No. 11, 1032-1045, doi: $10.1080 / 07408170802167639$

[9] Onut, S.; Tuzkaya, U. R.; Dogac, B. (2008). A particle swarm optimization algorithm for the multiple-level warehouse layout design problem, Computers \& Industrial Engineering, Vol. 54, No. 4, 783-799, doi:10.1016/j.cie.2007.10.012

[10] Liu, C.-M. (1999). Clustering techniques for stock location and order picking in a distribution centre, Computers \& Operations Research, Vol. 26, No. 10-11, 989-1002, doi:10.1016/S03050548(99)00026-X

[11] Petersen, C. G.; Aase, G. R.; Heiser, D. R. (2004). Improving order-picking performance through the implementation of class-based storage, International Journal of Physical Distribution \& Logistics Management, Vol. 34, No. 7, 534-544, doi:10.1108/09600030410552230

[12] Mantel, R. J.; Schuur, P. C.; Heragu, S. S. (2007). Order oriented slotting: a new assignment strategy for warehouses, European Journal of Industrial Engineering, Vol. 1, No. 3, 301-316, doi:10.1504/EJIE.2007.014689

[13] Ratliff, H. D.; Rosenthal, A. S. (1983). Order picking in a rectangular warehouse: a solvable case for the traveling salesman problem, Operations Research, Vol. 31, No. 3, 507-521, doi:10.1287/opre.31.3.507

[14] Petersen, C. G. (1997). An evaluation of order picking routing policies, International Journal of Operations \& Production Management, Vol. 17, No. 11, 1098-1111, doi:10.1108/ $\underline{01443579710177860}$

[15] Hwang, H.; Oh, Y. H.; Lee, Y. K. (2007). An evaluation of routing policies for order-picking operations in low-level picker-to-part system, International Journal of Production Research, Vol. 42, No. 18, 3873-3889, doi:10.1080/00207540410001696339

[16] De Koster, M. B. M.; van der Poort, E. S.; Wolters, M. (2010). Efficient orderbatching methods in warehouses, International Journal of Production Research, Vol. 37, No. 7, 1479-1504, doi: $10.1080 / 002075499191094$

[17] Henn, S.; Koch, S.; Wäscher, G. (2012). Order batching in order picking warehouses: a survey of solution approaches, Manzini, R. (Ed.), Warehousing in the Global Supply Chain, Springer, London, 105-137, doi:10.1007/978-1-4471-2274-6_6

[18] Roodbergen, K. J.; Koster, R. (2001). Routing methods for warehouses with multiple cross aisles, International Journal of Production Research, Vol. 39, No. 9, 1865-1883, doi:10.1080/ $\underline{00207540110028128}$

[19] Caron, F.; Marchet, G.; Perego, A. (2000). Optimal layout in low-level picker-to-part systems, International Journal of Production Research, Vol. 38, No. 1, 101-117, doi:10.1080/ 002075400189608

[20] Van Gils, T.; Ramaekers, K.; Caris, A.; Cools, M. (2017). The use of time series forecasting in zone order picking systems to predict order pickers' workload, International Journal of Production Research, Vol. 55, No. 21, 6380-6393, doi:10.1080/00207543.2016.1216659 
[21] Pan, J. C.-H.; Wu, M.-H. (2012). Throughput analysis for order picking system with multiple pickers and aisle congestion considerations, Computers \& Operations Research, Vol. 39, No. 7, 1661-1672, doi:10.1016/j.cor.2011.09.022

[22] Klodawski, M.; Jachimowski, R.; Jacyna-Golda, I.; Izdebski, M. (2018). Simulation analysis of order picking efficiency with congestion situations, International Journal of Simulation Modelling, Vol. 17, No. 3, 431-443, doi:10.2507/IJSIMM17(3)438

[23] Rao, S. S.; Adil, G. K. (2017). Analytical models for a new turnover-based hybrid storage policy in unit-load warehouses, International Journal of Production Research, Vol. 55, No. 2, 327-346, doi:10.1080/00207543.2016.1158428

[24] Scharma, S.; Shah, B. (2015). A proposed hybrid storage assignment framework: a case study, Journal of Productivity and Performance Management, Vol. 64, No. 6, 870-892, doi:10.1108/IJPPM-04-2014-0053

[25] Goetschalckx, M.; Ratliff, H. D. (1988). Order picking in an aisle, IIE Transactions, Vol. 20, No. 1, 53-62, doi: $10.1080 / 07408178808966150$

[26] Hall, R. W. (1993). Distance approximations for routing manual pickers in a warehouse, IIE Transactions, Vol. 25, No. 4, 76-87, doi:10.1080/07408179308964306

[27] Chen, F.; Wang, H.; Xie, Y.; Qi, C. (2016). An ACO-based online routing method for multiple order pickers with congestion consideration in warehouse, Journal of Intelligent Manufacturing, Vol. 27, No. 2, 389-408, doi:10.1007/s10845-014-0871-1

[28] Lin, C.-H.; Lu, I.-Y. (1999). The procedure of determining the order picking strategies in distribution center, International Journal of Production Economics, Vol. 60-61, 301-307, doi:10.1016/S0925-5273(98)00188-1

[29] Gibson, D. R.; Sharp, G. P. (1992). Order batching procedures, European Journal of Operational Research, Vol. 58, No. 1, 57-67, doi:10.1016/0377-2217(92)90235-2

[30] Rosenwein, M. B. (1996). A comparison of heuristics for the problem of batching orders for warehouse selection, International Journal of Production Research, Vol. 34, No. 3, 657-664, doi: $10.1080 / 00207549608904926$

[31] Parikh, P. J.; Meller, R. D. (2008). Selecting between batch and zone order picking strategies in a distribution center, Transportation Research Part E: Logistics and Transport Review, Vol. 44, No. 5, 696-719, doi:10.1016/j.tre.2007.03.002

[32] Petersen, C. G. (1995). Routeing and storage policy interaction in order picking operations, Decision Sciences Institute Proceedings, Vol. 3, 1614-1616

[33] Petersen, C. G.; Schmenner, R. W. (2007). An evaluation of routing and volume-based storage policies in an order picking operation, Decision Sciences, Vol. 30, No. 2, 481-501, doi:10.1111/j.1540-5915.1999.tb01619.x

[34] Chen, C.-M.; Gong, Y.; de Koster, R. B. M.; van Nunen, J. A. E. E. (2010). A flexible evaluative framework for order picking systems, Production and Operations Management, Vol. 19, No. 1, 70-82, doi:10.1111/j.1937-5956.2009.01047.x

[35] Cheng, C.-Y.; Chen, Y.-Y.; Chen, T.-L.; Yoo, J. J.-W. (2015). Using a hybrid approach based on the particle swarm optimization and ant colony optimization to solve a joint order batching and picker routing problem, International Journal of Production Economics, Vol. 170, Part C, 805814, doi:10.1016/j.ijpe.2015.03.021 